\title{
Lautaro Edén Wellington: viaje de retorno a las “zonas de contacto" de la Patagonia occidental
}

\author{
LAUTARO EDEN WELLINGTON: A RETURN TRIP TO THE “CONTACT ZONES” IN \\ WESTERN PATAGONIA
}

\section{LAUTARO EDÉN WELLINGTON: VIAGEM DE VOLTA ÀS “ZONAS DE CONTATO” DO OESTE DA PATAGÔNIA}

\author{
Paula Elena López Wood *1 \\ pelopez1@uc.cl
}

\section{Resumen}

A partir de la historia de Lautaro Edén Wellington-joven kawésqar enviado desde Patagonia occidental para formarse como militar en Santiago de Chile en la década de 1940_este artículo analiza las formas discursivas que han representado el viaje de retorno de Lautaro a su comunidad y su posterior fuga a los canales del archipiélago magallánico. El artículo se pregunta ¿de qué forma el relato de viaje protagonizado por Lautaro Edén Wellington enuncia una subjetividad del indígena del extremo sur que ha sido utilizada para sostener un discurso de dominación en dicho territorio? ¿Qué mecanismos utilizan aquellas narraciones para proyectar en Patagonia occidental un mundo mítico de naturaleza virgen inmerso en un tiempo ahistórico? Para responderlas, se trabajará el concepto de "zona de contacto" acuñado por la académica Mary Louise Pratt, quien sostiene que la literatura de viajes instala discursos coercitivos que contrastan con las formas de decir y adquirir conocimiento de las comunidades locales. Así, el artículo indagará en la posibilidad de dar con una versión de la historia de Lautaro que presente una subjetividad del indígena canoero con agencia y voluntad propia, para ofrecer alternativas a los discursos de dominación presentes en los textos analizados que han re-presentado dicho relato.

Palabras clave: literatura de viajes, Patagonia occidental, Kawésqar, nómades del sur
Abstract
Looking at the story of Lautaro Edén Wellington-a young Kawésqar sent from Western Patagonia to train as a military man in Santiago de Chile in the 1940s-this article analyzes the discursive forms that have represented Lautaro's return journey

\footnotetext{
$1 *$ Universidad católica de Chile

Tekoporá ${ }^{\circledR}$. Centro Universitario de la Región Este. Universidad de la República (C) López. (2021)

Este es un artículo de Acceso Abierto distribuido bajo licencia Creative Commons (CC BY NC 4.0)
} 
to his community and his subsequent escape to the channels of the Magellan archipelago. The article asks: in what way does the story about Lautaro Edén Wellington enunciate an indigenous subjectivity of the extreme south that has been used to sustain discourses of domination in that territory? What are the mechanisms these narratives use to project western Patagonia as a mythical world of virgin nature immersed in ahistorical time? To answer these questions, I will rely on the concept of the "contact zone" coined by the academic Mary Louise Pratt, who argues that travel literature installs coercive discourses that contrast with the ways of expressing and acquiring knowledge of local communities. Thus, the article will investigate the possibility of finding a version of Lautaro's story that presents a subjectivity of the indigenous canoeist with an agency and will of his own, in order to offer alternatives to the discourses of domination present in the analyzed texts that have re-presented his story.

Keywords: travel literature, Western Patagonia, Kawésqar, southern nomads

\section{Resumo}

Partindo da história de Lautaro Edén Wellington-um jovem Kawésqar enviado da Patagônia Ocidental para treinar como militar em Santiago do Chile na década de 1940-este artigo analisa as formas discursivas que representaram a jornada de retorno de Lautaro à sua comunidade e sua subsequente fuga para os canais do arquipélago de Magalhães. $O$ artigo questiona de que forma a história de viagem estrelada por Lautaro Edén Wellington enuncia uma subjetividade dos indígenas do extremo sul que vem servindo para sustentar um discurso de dominação no referido território? Que mecanismos essas narrativas usam para projetar na Patagônia ocidental um mundo mítico de natureza virgem imerso em um tempo a-histórico? Para respondê-las, trabalharemos o conceito de "zona de contato" cunhado pela acadêmica Mary Louise Pratt, que argumenta que a literatura de viagem instala discursos coercitivos que contrastam com as formas de dizer e de conhecer das comunidades locais. Assim, o artigo investigará a possibilidade de encontrar uma versão da história de Lautaro que apresente uma subjetividade do canoísta indígena com agência e vontade própria, para oferecer alternativas aos discursos de dominação presentes nos textos analisados que reapresentaram ditas história.

Palavras-chave: literatura de viagens, Western Patagonia, Kawésqar, southern nômades 


\title{
Introducción
}

\author{
¿Y si la desaparición es la herramienta de \\ sobrevivencia más evolucionada de todas? \\ -Zoo, Dir. Manuela Infante ${ }^{2}$
}

Puerto Edén, o Jetarktétqal, en lengua kawésqar, está emplazada en la costa oriental de la isla Wellington, Provincia de Última Esperanza, Región de Magallanes, zona austral de Chile. Puerto Edén es también el único punto insular habitado del intrincado archipiélago de Patagonia occidental; su acceso más cercano por el sur está en la ciudad de Puerto Natales, a 20 horas de navegación, y por el norte, en el poblado de Caleta Tortel, Región de Aysén, a 12 horas de navegación, cuando las condiciones del viento y el oleaje lo permiten a las embarcaciones que recorren los canales.

Rodeado de fiordos e islas cubiertas de selva fría y húmeda, montañas acantiladas con glaciares que caen desde Campo de Hielo Patagónico Sur, los "cuarenta rugientes" de los paralelos $40^{\circ}$ y $50^{\circ}$ donde se inserta el archipiélago magallánico y Puerto Edén, han constituido también una zona de exclusión al desarrollo y civilización de los centros urbanos de la zona austral de Chile. Descrita ya en 1957 por la antropóloga francesa Anette Laming como "zona medio vacía" (p. 27), la imposibilidad de construir caminos que conecten el mosaico de fiordos y canales, la geografía fracturada y los suelos pantanosos que impiden el desarrollo agrícola y ganadero, marginó a la única comunidad que se asentó en el archipiélago: la bahía de Puerto Edén, bautizado con el nombre bíblico por el historiador magallánico Mateo Martinic (2004), quien sería también intendente de la Provincia de Última Esperanza, mismo período que se crea en 1969 el Decreto Fundacional para incorporar a la etnia kawésqar al sistema de poblamiento nacional. Como los exploradores y científicos extranjeros que recorrieron Patagonia occidental siglos antes, Mateo Martinic (2004) usa el término "la última frontera" para describir el archipiélago magallánico:

Un laberinto que durante milenios fuera el territorio natural de los aborígenes marinos, por el que igualmente tantos navegantes se internaron a lo largo de los últimos cinco siglos, muchas veces a tientas e inútilmente, buscando inhallables rumbos australes. (p.15)

Aquellos cinco siglos de historia que alude Martinic comienzan con la circunnavegación del globo de la expedición de Hernando de Magallanes y su paso por el estrecho en 1520, y por ende, con la aparición de la escritura en la región gracias al registro que hace el cronista Antonio Pigafetta del cruce del Estrecho. Esos viajes exploratorios darán cuenta de escasas pero significativas "zonas de contacto"-concepto de la académica estadounidense Mary Louise Pratt-entre europeos e indígenas canoeros. En su libro Ojos imperiales: Literatura de viajes y

\footnotetext{
${ }^{2}$ ZOO es una obra de teatro estrenada en 2013 bajo la dramaturgia de Manuela Infante y la compañía Teatro de Chile. Recogiendo las observaciones de Darwin en su bitácora de viaje a Tierra del Fuego, ZOO replica la experiencia de los "zoológicos humanos". Ver: https://www.teatrodechile.cl/en/obras/zoo/
} 
transculturación, Pratt (2011) las describe así:

Las "zonas de contacto", van a ser espacios sociales donde culturas dispares se encuentran, chocan y se enfrentan (...) el espacio en que las personas separadas geográfica e históricamente entran en contacto entre sí y entablan relaciones duraderas, que por lo general implican condiciones de coerción, radical inequidad e intolerable conflicto. (pp. 31-33)

Pratt se inserta en una cadena de pensamiento que cuestiona las facultades del imperio para construir significado, con el propósito de descolonizar el conocimiento, la historia y las relaciones humanas (p. 21). De ese modo, la académica se ocupa de cuestionar la literatura europea de viajes en relación a la expansión económica y política iniciada alrededor de 1750. En lo que acontece con el territorio aquí descrito, encontramos ejemplos de zonas de contacto insertas en la literatura de viajes de expediciones realizadas a lo largo del archipiélago magallánico, como el caso del mencionado Pigafetta al describir a los patagones en 1520 o Juan Ladrillero (1557-58) quien, por ejemplo, hace la siguiente descripción de un grupo de kawésqar avistado en el canal Fallos, al sur del golfo de Penas, punto donde comienza el archipiélago magallánico ${ }^{3}$ :

La gente que hay en esta ensenada susodicha, son indios pescadores de mediano cuerpo y mal proporcionados. (...) No tienen ollas ni vasija, ni se han ollado sal entre ellos. Son muy salvajes y sin razón. (...) Traen sus vergüenzas de fuera sin ninguna cobertura. Son de grandes fuerzas. Traen como arma unos huesos de ballena a manera de dagas, y unos palos, como lanzuelas mal hechas. Andan en canoas de cáscaras de cipreses y de otros árboles. No tienen poblaciones ni casas, sino que hoy aquí, mañana en otra parte. (Ladrillero en Martinic, 2004, p.464)

Entre las expediciones de bandera inglesa, la que marca un antecedente crucial de encuentro entre europeos y kawésqar es el naufragio de la fragata HMS Wager (1741) donde su comodoro John Byron (1723-1786) relata el momento en que se encuentra con los kawésqar, enfatizando antes, en la sorpresa que les produce a los indígenas ver un espejo con su propia imagen ${ }^{4}$ : Eran gentes de estatura pequeña, muy morenas, y llevaban el pelo negro, largo y áspero desparramado sobre la cara. Debido al gran asombro que demostraban en su

\footnotetext{
${ }^{3}$ Un recuento de las expediciones que tuvieron lugar en el archipiélago magallánico, desde la expedición de Hernando de Magallanes en 1520 hasta mediados del siglo XX, incluyendo las exploraciones etnográficas de Joseph Emperaire en 1946 y Martín Gusinde en 1918 y 1924, se encuentra en el citado texto de Mateo Martinic "Archipiélago Patagónico: la última frontera". Para fines de este artículo, se mencionan aquellos relatos en donde el concepto de "zona de contacto" cobra significado de dominación, al modo en que lo entiende Mary Louise Pratt.

${ }^{4}$ En mayo de 1741, la fragata HMS Wager naufraga en la costa de la Isla Wager, Patagonia occidental. El relato del naufragio y supervivencia de los tripulantes está magistralmente narrado por el contramaestre John Byron, quien junto a un pequeño grupo logró sobrevivir gracias a la ayuda que le brindaron indígenas canoeros provenientes de la zona de Chiloé, permitiéndole después de dos años retornar a Inglaterra. Este evento habría sido uno de los primeros encuentros entre el hombre blanco europeo y los indígenas que habitaban este territorio (Byron, 2017).
} 
comportamiento, en sus gestos, así como el hecho de que no poseían algún objeto que hubiese podido proceder del hombre blanco, era evidente que jamás habían visto alguno. Su ropaje no era más que un pedazo de piel de alguna bestia puesto alrededor de la cintura, y algo tejido con plumas sobre los hombros. En vista de que no pronunciaban ninguna palabra en lengua conocida, ni contaban con ningún método para darse a entender, presumimos que nunca habían tenido contacto con los europeos (Byron, 2017, p.44).

Si bien las expediciones hidrográficas posteriores del HMS Beagle, Adelaide y el Adventure (1826-1830), atravesaron el mar del sur por la zona del estrecho de Magallanes, siendo su contacto con indígenas principalmente con el grupo yagán, importa mencionar las impresiones que tuvo el naturalista Charles Darwin en torno a los nativos del extremo sur durante su paso por los canales patagónicos, y que deja manifiesto en Los viajes del Beagle publicado en 1831. Esto, puesto que uno de los indígenas que llevarían consigo a bordo del Beagle sería el yagán Jemmy Button, quien como se verá más adelante, guarda relación con la historia de Lautaro Edén Wellington un siglo más tarde, en territorio kawésqar:

Jamás había visto yo, verdaderamente, seres más abyectos y más miserables (...) Estos desdichados salvajes tienen la talla escasa, el rostro repugnante y cubierto de pintura blanca, la piel sucia y grasienta, los cabellos enmarañados, la voz discordante y los gestos violentos. Cuando se ve tales hombres, apenas puede creerse que sean seres humanos, habitantes del mismo mundo que nosotros. (Darwin, 2019, p. 263)

Se puede inferir con estos tres ejemplos citados que persiste, en menor o mayor grado, una impresión del indígena del extremo sur con las siguientes características: un ser salvaje, precario, fuerte, que carece de vergüenza y que desconoce la mayoría de los utensilios y comodidades que proporciona la civilización. Asimismo, el territorio que habita produce una serie de significantes donde predominan el uso de adjetivos como lo "inexplorado", "virgen", y "vacío". Mary Louise Pratt identifica el sujeto que, provisto de cartografía y la información recabada tras la circunnavegación puede viajar y producir este tipo de paisaje y subjetividad en la literatura de viajes. Se trata de un sujeto ahistórico mundial europeo, masculino, laico e instruido; donde su conciencia planetaria es el resultado de su contacto con la cultura de la imprenta y es infinitamente más completa que las experiencias vividas por los marineros (Pratt, 2011, p. 69).

En esa línea, cabe preguntarse, ¿qué ocurre con la experiencia y el relato de viaje del sujeto indígena canoero de Patagonia occidental, como también de quienes han navegado anónimamente por estos canales, ya sea por subsistencia o necesidad? El lingüista Oscar Aguilera y el antropólogo kawésqar José Tonko han hecho un valioso aporte a este conocimiento con Relatos de viaje kawésqar publicado en 2013, al recuperar las formas de decir y narrar el viaje por los canales desde la subjetividad del kawésqar del siglo XX. En dicho texto se destaca cómo el conocimiento anclado a un oficio guarda relación con los accidentes geográficos y el clima, también, las vivencias que se desprenden a medida que se desenvuelve el viaje, puesto que de la transmisión verídica del trayecto depende el sustento y supervivencia de la comunidad. En este caso, el contenido de lo narrado y la 
transmisión legítima del relato de viaje previenen, literalmente, la muerte del grupo. Aguilera y Tonko escriben:

La narración del viaje utiliza un lenguaje más coloquial, es la historia portadora de noticias y de conocimientos geográficos (...) un conocimiento imprescindible para todo nuevo navegante kawésqar: quien no conoce las rutas ni sabe cómo llegar a los recursos, no sobrevive en ese territorio (p.28).

De lo anterior se infiere que verdad, narración y sobrevivencia son una triada indisoluble en la representación del viaje del sujeto canoero kawésqar del extremo sur. Haciendo un desplazamiento hacia la semiología y la exploración, encontramos en intelectuales occidentales-acaso viajeros de la mente-como Walter Benjamin una mirada fundacional en torno a oficios como el del navegante y el cazador y su innata condición de portadores de historias. En su ensayo El narrador, publicado por primera vez en alemán en 1936, Benjamin sostiene: "'Cuando se ha viajado, se tienen cosas que contar, suele decir la voz popular, imaginando al narrador como a alguien que regresa de un viaje lejano" (Benjamin, 2018, p. 253). Así también, el historiador italiano Carlo Ginzburg, en Mitos, Indicios, Emblemas, publicado por primera vez en 1989, advierte cómo en las formas indiciales de adquirir conocimiento los cazadores antiguos articulaban una narrativa específica: “El cazador habría sido el primero en 'contar una historia', porque era el único que se hallaba en condiciones de leer, en los rastros mudos (cuando no imperceptibles) dejados por la presa, una serie coherente de acontecimientos" (Ginzburg, 2009 p. 144). Para el historiador, el paradigma indicial tiene que ver con "formas de saber tendencialmente mudas-en el sentido de que, sus reglas no se prestan a ser formalizadas, y ni siquiera expresadas (...) En este tipo de conocimiento entran en juego elementos imponderables: olfato, golpe de vista, intuición" (p.163).

¿Cuáles serían, entonces, los indicios, las huellas, de los que se vale el habitante del archipiélago magallánico-vale decir, el indígena canoero kawésqar-para narrar y ejecutar su propio relato de viaje? ¿Cuáles son las formas de adquirir conocimiento para llevar a cabo la navegación e ir tras la obtención del alimento y la bahía apropiada para pernoctar en las noches y refugiarse de la tormenta? La casi inexistencia de testimonios kawésqar respecto a este asunto, en contraposición a la vasta literatura de viajes con que ha sido representada Patagonia occidental, da cuenta también de aquello que Mary Louise Pratt insiste respecto a la disciplina de la historia natural traída por la taxonomización europea, el systema naturae, que es capaz de imponer un cierto tipo de lenguaje, conocimiento y narración:

El sistema de la naturaleza pasó por alto las maneras que tenía de adquirir conocimiento las comunidades locales y campesinas dentro de Europa, tal como lo hizo con las maneras locales indígenas en el exterior (...) El ojo (letrado, masculino, europeo) que sostenía el sistema podía hacer familiares ("naturalizar") nuevos sitios/vistas inmediatamente en el primer contacto, al incorporarlos al lenguaje del sistema. (Pratt, 2011, pp. 71-73) 
Pratt se refiere a lo anterior como una "resemantización global", en el sentido de que en dicho imaginario se instala no solo una visión particular del paisaje, sino también del sujeto que habita ese territorio remoto e inexplorado, y por tanto, que invita a la civilización. Es, a fin de cuentas, la imagen mítica de Adán, el indígena en territorio virgen, la inocencia primigenia del buen salvaje que se infiere en las citas extraídas de aquellas "zonas de contacto" entre Ladrillero (1557), Byron (1741), Fitz Roy (1826) y los habitantes de los canales. Siguiendo el pensamiento de Pratt, se puede sugerir que la trampa o el peligro de la literatura de viajes y su intención "naturalista" producida por quien tiene el privilegio de viajar con cartografía para registrar y documentar, está en que, a diferencia de las formas explícitas de dominación que establece el colonialismo o la esclavitud, aquí se enfrenta a formas menos evidentes, y por lo tanto, aparentemente inofensivas. Pratt (2011) escribe: "La conversión de una naturaleza cruda al systema naturae es un gesto extrañamente abstracto y no heroico, un gesto que (aparentemente) no pone gran cosa en juego-por cierto, en ningún caso a las almas"(p.73). Lo que se intenta problematizar-e iluminar-en este artículo es que las formas de narrar una subjetividad del indígena sí manifiestan un sistema de dominio igualmente coercitivo. Es lo que se buscará argumentar con la historia de Lautaro Edén Wellington y los sucesos acontecidos en su viaje de retorno a Puerto Edén tras la instrucción militar, revisando diferentes formas discursivas en el campo del teatro, la narrativa y la etnografía, como también haciendo uso de entrevistas realizadas por la autora de este artículo durante trabajo de campo en Puerto Edén en 2019.

Puerto Edén se funda en 1936, cuando la Fuerza Aérea de Chile crea un puesto de aviación en esta bahía protegida de isla Wellington, en vista de la necesidad de tener una base donde cargar combustible para los hidroaviones que volaban desde Puerto Montt hacia Punta Arenas. Los años posteriores a la creación de la base se asientan grupos de kawésqar-quienes hasta entonces se dedicaban a la vida nómade por los canales, instalándose en puntos como el faro San Pedro e Isla Guarello-atraídos por el suministro de vestuario y alimento que los militares les proporcionaban. Durante ese período, llegan también pescadores desde el norte y loberos de islas como Melinka, Puerto Aguirre y Chiloé (Región de Aysén y Los Lagos) en busca de la abundancia que ofrecían los canales para el negocio peletero y de la pesca. Dicho encuentro entre militares, la comunidad kawésqar y loberos chilotes, es el escenario donde surgen los textos que se busca analizar en este artículo: la obra de teatro Ayayema (1964) de María Asunción Requena, la novela La última canoa (1976) de Osvaldo Wegmann y las obras etnográficas del matrimonio de antropólogos Joseph Emperaire (1946) y Anette Laming (1957).

El relato de viaje (partida, retorno y escape) de Petháyem Lautaro, también llamado en su comunidad como Terwa koyo o Brazo tieso en lengua kawésqar, por su forma de saludar a la bandera chilena, se recopiló primeramente en los libros Patagonia, Confín del mundo (1957) de Anette Laming y Los nómades del mar (1963) de Joseph Emperaire, pareja de antropólogos franceses que se instalaron en Puerto Edén entre 1946 y 1948 para estudiar la vida de los indígenas kawésqar. Emperaire constata en su libro que la instalación de la base de la FACH hizo que algunos kawésqar se acomodaran en las cercanías del puesto militar, aprovechando el alimento y vestuario que los militares les entregaban. El Estado de Chile, sostiene el antropólogo, no tardó en aprovechar la docilidad de los indígenas para 
iniciar la colonización, entregando precarias viviendas, asistencia médica y comida a los kawésqar, que poco a poco se animaban a dejar atrás la vida nómade para asentarse con sus perros y canoas, acomodándose a un nuevo estilo de vida. Fue también el comienzo de la inminente declinación de sus habitantes (Emperaire, 2002, p. 178). Según afirma Mateo Martinic (2004) en Archipiélago patagónico: la última frontera, antes del contacto con el hombre blanco, se estimaba que había unos 6.000 individuos de la etnia kawésqar. Una década después del establecimiento del puesto de aviación en Puerto Edén en 1936, la población había disminuido a menos de 90 individuos (p. 27).

Es en ese período, a fines de la década de 1930, cuando un sargento de la FACH y su esposa se encariñan con un joven kawésqar llamado Petháyem. Lo bautizan con el nombre de Lautaro Edén Wellington por la localidad y la isla y bahía de su proveniencia. ${ }^{5}$ En esa época, la población kawésqar se veía diezmada por enfermedades como tuberculosis y sífilis que azotaban a la comunidad dadas las condiciones de vivienda e higiene alimentaria desde que se habían asentado a expensas de la FACH. En ese contexto, el gobierno del presidente de la época, Pedro Aguirre Cerda, dicta una ley de protección indígena, con el objetivo de radicar a los indígenas en Puerto Edén y poco a poco llevarlos a una vida más civilizada. El experimento que ocurrió con Lautaro Edén Wellington se encontraba al amparo de esa ley de protección (Emperaire, 2002, p. 125). El propósito de dicho ensayo antropológico-liderado por militares-era enseñarle a Lautaro los modos de vida del hombre blanco para luego retornarlo a la comunidad de Puerto Edén y así él mismo expandiera la civilización (Laming, 1957, p. 78). El experimento resonaba con el de los niños yaganes Jemmy Button, Fueguia Basket, York Minster y Memory Boat, yaganes de Tierra del Fuego, quienes en 1871 el comandante Robert Fitz Roy decidió llevar a bordo del HMS Beagle para educarlos en Inglaterra y años más tarde traer de regreso a los sobrevivientes a su tierra con el propósito de "transformar a esa tribu sin ley, disciplina ni religión" (Bridges, 2018, p. 14). El desenlace fue trágico. Como recopila Lucas Bridges en El último confín de la tierra, hijo del misionero inglés Thomas Bridges (primer hombre blanco en vivir en Tierra del Fuego fundando la Estancia Harberton en 1886), años después de su retorno a la vida nómade en los canales, Jemmy Button lideró la venganza con ayuda de la comunidad yagán, quienes dieron muerte a los sacerdotes que venían a expandir la misión anglicana al sur de Tierra del Fuego (Bridges, 2018, p. 16).

Los oficiales de la FACH de Puerto Edén hicieron caso omiso a la historia de Jemmy Button al enviar a Lautaro o Petháyem a Punta Arenas y educarlo en un colegio de la orden salesiana, hacerlo ahijado del presidente de la república Pedro

\footnotetext{
${ }^{5}$ En la primera fase de conquista española al territorio que llegaría a ser Chile, hubo un legendario líder mapuche llamado Luan-Taro (1534-1557). Capturado a los 11 años fue re-nombrado por los españoles como Lautaro y convertido en servidumbre. Años más tarde, Lautaro se fugaría del conquistador Pedro de Valdivia y los españoles, liderando como Toqui una rebelión mapuche donde aplicaría las tácticas de batalla hispanas aprendidas, las cuales fueron determinantes para la resistencia mapuche durante la Guerra de Arauco. Como se verá más adelante en este artículo, la historia del Lautaro mapuche del siglo XVI va a resonar de cerca con el desenlace y rebelión de Lautaro Edén Wellington en Patagonia occidental en su fuga y rebeldía ante la instrucción militar que recibe en su juventud (ver Memoria Chilena).
} 
Aguirre Cerda y enviarlo a Santiago para formarlo en la Escuela de Especialidades de la Fuerza Aérea de Chile. Así, en 1939, Lautaro viaja a la capital, donde pasa ocho años de su vida, aprende a usar el fusil durante su instrucción y sale con el grado de cabo segundo y mecánico de aviación. En 1947 lo envían por un mes a Puerto Edén, donde ejerce su jerarquía y superioridad ante su comunidad. En el libro Patagonia, confín del mundo, la antropóloga Anette Laming (1957) sostiene que ya entonces, la actitud de Lautaro no auguraba nada bueno (p. 275). Rehusó reconocer a sus padres y hablar a sus antiguos amigos, a pesar de que no había olvidado su lengua materna. Tras dos años de permanencia en Puerto Edén sirviendo en la Radio Estación de Puerto Edén, Lautaro decide equipar una embarcación y desaparecer junto a su familia, sin dejar rastro alguno.

Asimismo, para Laming, el período entre 1949 y 1952 - años en que Lautaro retorna a la vida en los canales tras diez años de "vida civilizada"-carece de documentos o testimonios que narren de primera fuente lo que ocurrió durante ese período de retorno a la vida nómade, donde lo que prevaleció fue el intercambio con chilotes y loberos en el laberinto de canales de Patagonia occidental y la costa del Océano Pacífico. En ese período de libertad recobrada, mientras un pequeño grupo de kawésqar permanecía en Puerto Edén, Lautaro y su tripulación forman cerca del faro San Pedro-al sur del golfo de Penas, donde solía asentarse una importante comunidad kawésqar dada la presencia de la Armada que los abastecía con alimento y algo de vestuario-una comunidad dedicada a la caza de animales de pieles finas como nutrias. Para los kawésqar, insiste Anette Laming, esos tres años fueron un período de euforia: libertad de acción reconquistada, retorno a la vida nómade, posibilidad de frecuentar sin restricción a los loberos, siempre listos para suministrarles vino y alcohol a cambio de mujeres o pieles, todo lo que mitigaba en sus recuerdos los malos tratos habituales de los chilotes, su papel de esclavos y los asesinatos (p. 275). Tiempo después, a comienzos de 1953, los periódicos de Punta Arenas recibieron la noticia de que Lautaro Edén Wellington, sorprendido en los canales del oeste por una tormenta, se había ahogado con varios indígenas en el canal Fallos. Éste era, al menos, el relato de los sobrevivientes. Después del trágico suceso, ningún kawésqar volvió a escaparse de Puerto Edén (Laming, 1957, p. 277). "Es difícil dar datos precisos sobre este período de la vida de los alacalufes, pues, fuera de los loberos, totalmente incapaces de observación y descripción, no había ningún blanco de testigo", sostiene Joseph Emperaire en Los nómades del mar (p. 128). Así, las razones que motivaron a Lautaro a escaparse con los suyos y lo ocurrido durante esos años hasta su desaparición en el canal Fallos que lo llevó a la muerte, queda suspendido en el misterio para quienes conocieron a partir de textos etnográficos y de ficción aquel relato.

Tanto Laming como Emperaire constatan que los navegantes chilote-huilliche se aprovechaban del furor que producía en los indígenas sus embarcaciones como cúteres y lanchas para ofrecerles cualquier cosa a cambio: alcohol, galletas, azúcar, tabaco y municiones. Y que también robaban sus pieles, raptaban y violaban a sus mujeres. Si se enfrentaban a una negativa, dice Laming, era habitual que terminaran en sangrientos asesinatos (p. 325). Lautaro fue testigo de esa cruenta zona de contacto entre loberos y pescadores chilotes-huilliches y kawésqar. Esos conflictos serán también problematizados en las siguientes obras 
de ficción a analizar.

La dramaturga chilena María Asunción Requena (1915-1986) escribe en 1964 la obra de teatro Ayayema, la cual se escenifica en el momento en que Lautaro retorna a Puerto Edén tras la instrucción militar, narrando en un drama a dos partes los consecuentes enfrentamientos con loberos, chilotes, sargentos y su propia comunidad. La obra, así, instala a Lautaro como vocero y representante indígena en un momento de ampliación de retóricas pedagógicas y nacionalistas, que guardaban coherencia con el lema "gobernar es educar" promovido por el gobierno de ese entonces, el del ex presidente Pedro Aguirre Cerda (quien gobernó entre 1938 y 1941), quien, por lo demás, fue nombrado padrino de Lautaro Edén Wellington durante su visita a Punta Arenas en el verano de 1939, cuando Lautaro estudiaba en el colegio salesiano de esa ciudad.

En la obra Ayayema de Requena, ${ }^{6}$ la comunidad kawésqar, liderada por el sabio Kethoyo, se niega a someterse a las órdenes que impone Lautaro al retornar a Puerto Edén con el grado de cabo segundo. Lautaro intenta someter a los indígenas con marchas y maniobras que terminan en fracaso. Insistentemente, los persuade de aprender los modos de vida del chileno, ya sea en su mercancía, tecnología, lengua, vestuario y alimentos. Lautaro cree que con esa actitud liberará a los kawésqar, salvándolos de su inminente muerte y desaparición. Sin embargo, lo que ocurre es la repetición de un discurso de apoderado que los militares han impuesto previamente con él al hacerlo ahijado del presidente Pedro Aguirre Cerda, cambiarle el nombre y llevarlo a Santiago a formarse en la Fuerza Aérea de Chile. Sin darse cuenta, Lautaro se ha vuelto un esclavo de la ideología instalada por los centros dominantes urbanos, reproduciendo la relación coercitiva Indígena-Ahijado / Estado-Padrino, que luego, al regresar, pretende recrear con sus pares. Así queda evidente en el siguiente fragmento de la obra:

LAUTARO. De qué te vale ser fuerte si no eres libre...Y no eres libre... (busca cómo expresarse) porque... porque no sabes. Y no sabes hasta que entre aquí (le coloca el dedo en la frente) cuánta azúcar vale una foca, y cuánta harina y cuánto arroz la piel de lobo.

KETHOYO.- Yo saber cuánto galeta, cuánto tappónac...

LAUTARO.- ¿Estás loco? ¡Tappónac! ¿Te han dado alguna vez un cartucho para tu rifle? Sin pólvora puede ser. No, Kethoyo, no sabes nada aún. Pero aprenderás. [...] Tendremos nuestro barco, como los blancos. Y tendremos un gran depósito de pieles, como los blancos. Y vendrán ellos a buscarnos. Y a ofrecer lo justo. Cuando lo aprendas todo, te respetarán y hablarán de ti como un hombre que sabe hacer buenos trueques. Dirán: Es Kethoyo, no se le puede engañar. (Señala una gaviota que pasa graznando y Kethoyo mira con desesperación) Kaw-kaw sabe. Es libre, porque otra gaviota le enseñó. Come y vuela y ahora nadie la engaña. Kaw kaw aprende y obedece. (Requena, 1979, pp.

\footnotetext{
${ }^{6}$ Ayayema es en el imaginario kawésqar, un espíritu poderoso y maligno, que habitaba durante el día los pantanos y turbales y en la noche rondaba la espesura de los bosques junto a las costas. Dueño del viento, lo manejaba a su antojo, desatando las tempestades que castigaban y hundían las canoas (Martinic, 2004, p. 56).
} 
404-406)

En Ayayema, Kethoyo es el anciano kawésqar que representa la sabiduría, la fuerza y la renuencia a adquirir las conductas de los chilenos. El personaje de Kethoyo opera como el indígena que niega a subyugarse. Quiere conseguir su propio alimento, salir en su canoa y cazar. No le interesa la caridad de los militares. Pero para ser libre, para ser respetado, insiste el Lautaro de Ayayema, Kethoyo debe someterse a su tecnología (el cutter), a sus modos de intercambio comercial (saber cuánto vale una foca y el lobo) y obedecer. Su condición de indígena lo revela como insuficiente, aunque su etnia ha sobrevivido por más de seis mil años la llegada del blanco colonizador a ese territorio. Lautaro, en cambio, siente cariño y acepta a sus pares indígenas, pero solo en la medida en que se adapten a las normas de estilo y conducta de los blancos. La siguiente escena condensa también la premisa circulante: la problemática entre apadrinar, sustituir, re-presentar al otro (el indígena canoero), en contraposición a hacerlo hablar por sí mismo, ponerlo en escena, significarlo.

LAUTARO. (con mucha paciencia). Habla en cristiano, Kethoyo. Lo has aprendido muy bien. (Pausa). He dado orden que nadie se aleje de la isla sin mi autorización. Yo mando aquí, Kethoyo, y tú obedeces. Ahora, contéstame: ¿Por qué te ibas y a dónde?

KETHOYO. (Después de un momento se decide a hablar. Lo hace con voz suave, pero firme). Kethoyo buen cazador, fuerte en árbol. (Hace un ademán enérgico de dar un hachazo). Tener buona canoa. (Con orgullo.) Nuova.

LAUTARO. Sí, es cierto. Tu nueva canoa es ligera como la foca y fuerte como la ballena. La has trabajado muy bien, Kethoyo. Un día de estos iremos juntos a cazar.

KETHOYO. Yo cazar, y capetén crestiano no venir aquí. Yo ir a buscar capetén.

LAUTARO. ¿Por qué? No lo necesitas. Guarda tus pieles. Yo te doy comida.

KETHOYO. (Con dignidad simple) Yo, cazar mi comida..., no queriendo tuyo... (Se esfuerza por encontrar las palabras que traduzcan sus sentimientos). Yo quieto aquí...Yo no querer quieto aquí... (Sigue el vuelo con el índice. Luego se vuelve hacia el mar y dice profundamente, señalándolo). ¡Arka-aloé!

LAUTARO. (Siente con intensidad la idea del indio) Te entiendo, Kethoyo, te entiendo. (Se acerca a él y juntos miran hacia el mar). Más allá..., siempre más allá... De isla en isla... (Se exalta), cazando..., viviendo... (Se calma), pero también muriendo. Y yo no quiero que mueras. No quiero que nadie más se muera. (Requena, 1979, pp. 388-394)

Hay un momento, hacia el final de Ayayema, en que Lautaro enuncia su nombre de origen: Petayem Terwa Koyo. Es la única vez en toda la obra que sucede esto, y lo hace para reclamar justicia por su pueblo, justo después que muere Kethoyo en manos de los loberos que buscaban robarle las pieles y violar a las 
mujeres kawésqar. "Y yo sabré matar, uno por uno, a cada rata inmunda que se encuentre en los canales. Yo, Petayem Terwa Koyo...Yo los mataré. Por cada indio muerto, dos cristianos... Dos cristianos por cada indio muerto" (Requena p. 75). Sin embargo, esa voluntad de justicia o venganza, ese efímero destello de conciencia se diluye en la obra cuando la comunidad kawésqar parte a los canales y Lautaro opta por quedarse en Puerto Edén solo, manteniéndose como parte de la comunidad chilena y resguardando el puesto militar.

LAUTARO. Adonde van no puedo seguirlos. Mi puesto está aquí. ... Donde haya un indio siempre habrá un blanco acechando. Pero mientras quede un indio, mientras respire un indio en los canales, aquí me quedaré. Y cuidaré su choza y su canoa. (Requena, 1979, pp. 615-18)

Puerto Edén se transforma, así, en una suerte de umbral en la obra de teatro Ayayema, espacio intermedio donde Lautaro no puede dejar de replicar las conductas de apoderado con la comunidad a la que él mismo pertenece. Lautaro no es capaz de ver esa realidad y aquella es la tragedia del personaje. Si bien María Asunción Requena opta por dejar a Lautaro ciego ante los sistemas de dominación a los que está sometido, el valor de la obra Ayayema está en articular desde la sátira los discursos de poder, coerción y sometimiento de indígenas a militares, y ante todo, visibilizar cómo continúan perpetuándose en formas aún más complejas y problemáticas aquellos modos de representar a estas comunidades. ${ }^{7}$

En el ámbito de la narrativa, la novela La última canoa, publicada en 1976 por el escritor suizo-chileno Osvaldo Wegmann (1918-1987), cuenta la historia de Lautaro desde su partida al colegio salesiano en Punta Arenas hasta el trágico desenlace de la muerte en los canales cuando se fuga con un grupo familiar de su comunidad. Wegmann, quien estuvo varias veces en Puerto Edén, cuenta en una crónica publicada en 1983 en el diario magallánico La Prensa Austral y recopilada por Jorge Díaz Bustamente en De ayer y hoy, Crónicas de Osvaldo Wegmann Hansen, cómo se sintió impactado por la historia del indígena, su vínculo con el mundo aéreo y su retorno a la vida ancestral. De hecho, a través de la investigación realizada por el propio Wegmann se conoce el destino final de Lautaro: el 8 de mayo de 1950, a la altura del canal Fallos, frente a la isla Campana, fue hallado el cadáver de uno de los tripulantes de la chalupa aparejada, Guillermo Edén. Los demás, Lautaro y su madre, Isabel, Arturo Messier y María Campana habían desaparecido en el mar. La noticia fue transmitida por la Radio Estación de la FACH. El parte oficial consignó que la embarcación había naufragado, soprendido por un williwaw. Más tarde, la FACH optó por darlo de baja "por razones de servicio," lo que evitó que Lautaro fuese considerado un desertor. Sus familiares, aseguraron

\footnotetext{
${ }^{7}$ La académica Andrea Casals Hill, en un interesante artículo llamado Puerto Edén: ¿puerto o paraíso? Una lectura ecocrítica de Ayayema, de María Asunción Requena, analiza el lenguaje utilizado en el texto dramático, aludiendo, por ejemplo, a que Requena nombra indistintamente a los indígenas como "kawésqar" y "alacalufes", sin considerar que el término alacalufe ha sido usado de forma peyorativa para referirse a esta etnia. También, destaca el habla con que la dramaturga sitúa a los indígenas, siempre en tiempo infinitivo, como indicio de un estado de conciencia que vive solo en el presente. Sin dejar de lado estos planteamientos, este artículo considera que Requena sí logra dotar de una subjetividad novedosa al indígena kawésqar del siglo XX, principalmente con los personajes femeninos que protagonizan la obra, como es el caso del personaje de Mahuana.
} 
que había emprendido un viaje para reencontrarse con sus antepasados (Díaz, $1999,17)$.

La presencia del concepto de atavismo está fuertemente presente tanto en el citado parte oficial como en la novela de Wegmann, al representar la subjetividad del indígena que, tras experimentar de cerca la civilización, siente el llamado inapelable de la naturaleza y de su raza. Lo anterior queda en evidencia en el siguiente fragmento de la novela, durante una conversación entre Petáyem, rebautizado en La última canoa como Lientur Messier, y Washington, el único amigo que hace durante la instrucción militar en Santiago. Wegmann (1976) escribe en la novela:

- La verdad, es que tarde o temprano, tendré que regresar a mi tierra. No te miento, Washington, si te digo que ha cesado para mí y el embrujo de las grandes ciudades, las maravillas de la civilización, el atractivo de mi profesión de mecánico. Hoy día ajusto tuercas con la misma suficiencia y tranquilidad con que un alacalufe despega cholgas en las rocas de Puerto Edén, como una cosa de rutina, sin importancia. Pero mientras tanto, recuerdo los canales y los fiordos silenciosos; las canoas de los nativos, humeando bajo la lluvia; los viejos alacalufes junto al fuego, hablando del tiempo, de la marea, del viento y de los pájaros.

- Es el atavismo, Petayém. ¿Sabes tú qué es el atavismo?

- Yo diría que es un deseo natural de volver a vivir en el medio en que me crié. (p. 55)

La circularidad con que es retratada la historia de Lautaro en La última canoa y la afirmación de que retorna porque-como el yagán Jemmy Button retornado de Inglaterra-siente el llamado atávico de la naturaleza, da cuenta de un tipo de representación donde el indígena es concebido como perteneciente a un mundo alejado de la cultura, en este caso, al universo inhóspito, vírgen e inexporado de los canales patagónicos, acaso la "última frontera" acuñada por Mateo Martinic o la "zona medio vacía" con que la describe Anette Laming. Así como el relato de Jemmy Button se ha definido como "la historia de un gran fracaso" de la civilización ${ }^{8}$, Wegmann va a instalar a Lautaro en una subjetividad indígena nostálgica, postal romantizada donde no hay más remedio para el indígena que retornar al embrujo de los canales, al amor de una mujer de su raza, a la vida primitiva, a la construcción de la última canoa kawésqar y finalmente, a la muerte. De ese modo, el título de la novela, La última canoa, pone de relieve el valor simbólico de esta embarcación como vestigio de una etnia que, para el autor, está también por desaparecer. La novela de Wegmann, por tanto, repliega la ideología en que se inscribe el experimento educativo generado con Lautaro Edén, la función pedagógica del indígena instruido por el militar y el Estado. Lo anterior queda evidente en los diálogos entre Lautaro y el sargento Mayer, personaje que en la novela está a cargo de la radio estación de Puerto Edén.

8 "Es la historia del fracaso de un hombre y de su tentativa, arriesgada y noble, de incorporar a la civilización occidental y sumir en cultura cristiana a un pequeño grupo de indígenas nativos de Tierra del Fuego" (Subercaseux citado en Goic, 2004, p. 501). 
Se bien lo que dice el reglamento. El sargento Mayer, que me conoció de niño, cree que aún soy un alacalufe inculto y me trata como a un indio. Se olvida que soy cabo de la aviación, egresado de la escuela de especialidades, consciente de mis deberes y atribuciones (Wegmann, 1976, p.63).

Durante una sucesión de viajes consecutivos a Puerto Edén durante el año 2019, tuve la oportunidad de entrevistar a navegantes chilote-huilliches que llegaron de niños en cúteres y lanchas veleras a mediados del siglo XX a esta localidad. Los testimonios recopilados en esos tres viajes entre julio y diciembre de 2019 permitieron ahondar en torno a los trayectos recorridos, principalmente entre Puerto Edén y el Golfo de Penas, las estrategias de cacería, formas de orientarse durante la navegación, creencias y supersticiones relativas al viaje. En la sección final de este artículo busco dar cuenta de cómo esos testimonios y narraciones orales que circulan al interior de la comunidad de Puerto Edén pueden aportar una mirada novedosa a la historia de Lautaro Edén Wellington y las versiones literarias que han representado su historia de vida y muerte.

El más significativo de estos testimonios es el de un grupo de pescadores de Puerto Edén que viajó sucesivas veces junto a los kawésqar en la década del 60' al golfo de Penas para buscar el loco y el erizo en lanchas a vela, cuenta que durante esos trayectos que duraban dos o más meses, no era posible cargar comida para tal cantidad de tiempo. Los mariscos, siempre disponibles, solían descomponerles la digestión al cabo de unas semanas por el exceso de salobridad. Para acceder a otras fuentes de alimento, los kawésqar les enseñaron a los pescadores chilotes-huilliches técnicas de sobrevivencia para capturar aves como patos quetros y cormoranes durante las noches de luna llena, con trampas de liana boqui y fuentes de luz que cargaban a bordo, encandilando a las aves que anidaban sobre los barrancos. Era la forma con que los kawésqar solían abastecerse de alimento durante la vida nómade por los canales. El siguiente fragmento editado corresponde a una entrevista realizada durante trabajo de campo en diciembre de 2019 y se concentra en uno de los viajes realizados por el grupo de pescadores chilote-huillliches junto a un grupo kawésqar a lo largo de esos trayectos realizados en la década del 70':

Llegamos a un puerto que llamamos Calcetín e hicimos campamento, al lado sur de la isla Byron. De repente, en la noche, escuchamos unos lamentos, unos lamentos de persona. Me llamó la atención, porque ahí no anda gente. Uno de los kawésqar que andaba conmigo me dijo de qué se trataba. Ahí supe. Ellos no cuentan, son secretos para sus cosas, se las guardan. Resulta que años atrás llevaron a un par de niños a Santiago. El sargento oficial a cargo de la Fuerza Aérea de Chile con su señora le habían tomado cariño a un par de niños, les dieron educación, y a uno le pusieron Lautaro. Él entró a la Fuerza Aérea y salió con el grado de sargento segundo. Con ese grado se vino acá, volvió a Puerto Edén, a ver a su gente.

Resulta que Lautaro volvió a Edén y vino a cargo del puesto de la Fuerza Aérea. Pero vino para hacer justicia por su gente. Así que equipó 4 embarcaciones pequeñas a remo, las cargó con artillería, fusiles, 
municiones de la FACH y se fue para afuera, a los canales, a hacer justicia.

Antiguamente, acá pasaron muchas cosas muy malas. La gente que venía de las islas de Aysén, de Melinka, los chilotes que venían a trabajar las pieles, mataron a muchos kawésqar. Por quitarles las pieles, por quitarles las mujeres un rato, por raptarlas. Mataban de a 30, de 40. Es que antes, cuando uno salía, cuando uno andaba con las pieles, traía escopeta, rifle, cajas de tiro. Y así, cuánta gente mataron, gente antigua que mataba a los kawésqar. Estos viejos venían de Puerto Aguirre, de Melinka, venían matando. Mi finada mamá me conversaba y mi abuela igual, de Ñancupel, un chilote malo. Más maldito que todos los malditos juntos. Según él, mató 99 personas. De todas clases de gente. Entre niños, mujeres y adultos, porque asaltaba los barcos, era pirata.

Así, cuando Lautaro se fue, chilote que pillaba él lo mataba. Mata y mata; mata y mata tal como los otros hicieron con su gente. Su gente no dice nada de eso, no comenta nada. Eso lo conversa uno porque lo sabe bien, porque su misma gente lo ha contado.

Según lo que contaban los relatos, Lautaro llevaba cajas de fierro con cosas que encontraron, cosas que encontró mientras andaba navegando, y entre puerto Cangrejo y Calcetín rodearon la isla Byron por fuera y los tapó la mar, justo ahí. Se ahogaron todos, se salvó una pura mujer que andaba con ellos. Su misma gente la encontró en la playa. Y eso eran los lamentos que yo sentí cuando fuimos a pescar. ${ }^{9}$ Nos estaban penando. Los lamentos eran donde Lautaro estaba ahogándose, donde la mar los estaba tapando. ${ }^{10}$

Este fragmento extenso ofrece una perspectiva distinta de la historia de Lautaro o Petáyem a la abordada en las representaciones revisadas anteriormente. En el relato del pescador que viaja junto a los kawésqar años después de la desaparición y muerte de Lautaro, se abre una versión inusitada en torno al final de esta historia. Aquí surge un relato que circula entre el mito y el secreto resguardado por la oralidad de la propia comunidad, oralidad que transmite un conocimiento acumulado por generaciones y que solo parece darse al interior del trayecto de un largo viaje de subsistencia en una de las zonas más complejas de navegar de Patagonia occidental, las cercanías del golfo de Penas. Esta versión, además, le da agencia y voluntad propia al sujeto indígena narrado, ya que concentra su argumento en la acción de hacer justicia frente a pescadores y loberos que robaban sus pieles y raptaban a sus mujeres para incluso abusar de ellas. Así, cuando Lautaro se apropia de las armas, fusiles y municiones que le entrega el Estado de Chile a través de la instrucción militar de la FACH, cuando apareja la chalupa y se fuga a los canales para volver a la caza y a su vez vengarse de

\footnotetext{
${ }^{9}$ La costa de la isla Byron mencionada coincide con el punto donde se han encontrado restos del naufragio de la mencionada fragata HMS Wager en 1781.

${ }^{10}$ Entrevista realizada por la autora de este artículo durante trabajo de campo en diciembre de 2019 durante diversas visitas a Puerto Edén. Entrevista realizada, transcrita y editada con el consentimiento del entrevistado. El nombre del entrevistado se ha optado por dejar en anonimato.
} 
pescadores chilotes y huilliches, lo que hace es también un acto de restauración. Esta historia es importante porque implica la aparición de una voluntad inédita en la figura de Lautaro ya que, ante todo, hace aparecer una subjetividad con voz propia que contrasta con la voz re-presentada del Lautaro apadrinado de la obra Ayayema, o de la novela La última canoa con su retorno al atavismo, incluso al de la narración de los textos etnográficos de Laming-Emperaire, cargados de sesgos de valor.

El relato de los pescadores es importante, porque si bien circula a modo de mito, incluso cercano a la superstición de las experiencias del viaje, ofrece una mirada donde el punto de vista paternalista en torno a Lautaro se vuelve secundario, así también desaparece la idea de fracaso de civilizar a los márgenes, incluso el retorno de Lautaro a Puerto Edén no responde al llamado irrefrenable del atavismo, sino que a la idea de volver por su gente. En la historia secreta circulante de los habitantes de Puerto Edén, Lautaro es un sujeto con voz, cuerpo y discurso propio, quien, tal como el Lautaro mapuche que se libera de la servidumbre para hacer uso de las tácticas de guerra hispanas aprendidas y transformarse en Toqui en la Guerra de Arauco, aquí será el aprendizaje adquirido durante la instrucción militar lo que le permite a Lautaro utilizar los fusiles de la FACH para hacer justicia con y por su pueblo, hasta que los mismos canales y los wiliwaws de Ayayema le dan muerte en el golfo de Penas.

Habría que preguntarse si la historia de justicia de Lautaro permanece reservada porque circula como secreto entre los habitantes de Puerto Edén, o si acaso incomoda a las entidades políticas, sociales y culturales de la época, quienes con función pedagógica, apadrinadora y/o civilizadora buscan re-presentar en imaginarios una subalternidad indígena desde textos literarios y la literatura de viajes. En la versión de los pescadores de Puerto Edén, el viajero, Petháyem, se formula ya no en la versión pasiva del buen salvaje que habita un territorio virgen sumido en un tiempo ahistórico, sino que se erige como un sujeto que incomoda, porque tiene agencia y voluntad propia.

Queda pendiente retornar a Puerto Edén para recopilar nuevos testimonios de sus habitantes que permitan profundizar en este tipo de narraciones que circulan de forma oral en torno a la historia de Lautaro Edén Wellington y otros relatos de viaje, y así, ver la posibilidad desafiar las "zonas de contacto" coercitivas identificadas en el género de la literatura de viajes, en un territorio que para muchos continúa siendo concebido como "la última frontera".

\section{Referencias}

Aguilera, 0. y Tonko, J. (2013). Relatos de viaje kawésqar. Nómadas canoeros de la Patagonia Occidental. Temuco, Chile: Ofqui Editores.

Benjamin, W. (2018). Iluminaciones. Trad. Jesús Aguirre y Roberto Blatt. Colombia: Taurus. 
Bridges, E. L. (2018). El último confín de la Tierra. Trad. María Magdalena Briano. Buenos Aires, Argentina: Sudamericana.

Byron, J. (2017). La pérdida de la fragata Wager. Naufragio y supervivencia en la patagonia. Trad. Juan Manuel Vial. Santiago, Chile: Ediciones Universidad Diego Portales.

Casals, A. (2012). Puerto Edén: ¿puerto o paraíso? Una lectura ecocrítica de Ayayema, de María Asunción Requena. Apuntes de Teatro,(134). pp. 54-65.

Darwin, Ch. (2019). Los Viajes del Beagle (Diarios y Observaciones 1832-1836). Buenos Aires, Argentina: Eudeba.

Díaz, J. (1999) De Ayer y de Hoy. Crónicas de Osvaldo Wegmann Hansen. Punta Arenas, Chile: Comercial Atelí y Cía. Ltda.

Emperaire, J. (2002). Los nómades del mar. Trad. Luis Oyarzún. Santiago, Chile: Lom Ediciones.

Ginzburg, C. (2009). Mitos, emblemas, indicios. Morfología e historia. España: Editorial Gedisa.

Goic, C. (2004). La mirada oscura de Jorge Díaz. Santiago, Chile: Ediciones U. Católica.

Laming, A. (1957). En la Patagonia, confín del mundo. Trad. José Zañartu. Santiago, Chile: Editorial del Pacífico.

Martinic, M. (2004). Archipiélago magallánico: La última frontera. Punta Arenas, Chile: Ediciones de la Universidad de Magallanes.

Memoria Chilena. El toqui Lautaro. Santiago: Biblioteca Nacional de Chile. Recuperado de: http://www.memoriachilena.gob.cl/602/w3-article-721.html

Pratt, M. L. (2011). Ojos imperiales: literatura de viajes y transculturación. Trad.

Ofelia Castillo. Buenos Aires, Argentina: Fondo de Cultura Económica.

Requena, M. A. (1979). Teatro. Ayayema. Santiago, Chile: Editorial Nacimiento.

Subercaseux, B. (1965). Jemmy Button. Santiago, Chile: Ercilla.

Wegmann, O. (1976). La última canoa. Santiago, Chile: Hersaprint. 